\title{
Effect of Iron Gel on Dentin Permeability
}

\author{
Sílvia Helena de Carvalho SALES-PERES \\ João Victor Donazan REINATO \\ André de Carvalho SALES-PERES \\ Juliane Avansini MARSICANO \\ Department of Pediatric Dentistry, Orthodontics and Community Health, Bauru Dental School, \\ USP - University of São Paulo, Bauru, SP, Brazil
}

\begin{abstract}
This study evaluated in vitro the effect of an experimental gel containing iron on the reduction of hydraulic conductance of dentin. Thirty-six 1-mm-thick dentin discs obtained from extracted human third molars were divided into 3 groups of 10 specimens each. The groups corresponded to the following experimental materials: $1.23 \%$ acidulated phosphate fluoride gel, $\mathrm{pH} 4.1 ; 3 \%$ potassium oxalate gel, pH $4.1\left(\mathrm{Oxa}_{-\mathrm{Gel}}{ }^{\circledR}\right)$; and iron sulfate gel $\left(10 \mathrm{mmol} / \mathrm{L} \mathrm{FeSO}_{4}\right), \mathrm{pH} 4.1$. The gels were applied to dentin under the following conditions: after $37 \%$ phosphoric acid and before $6 \%$ citric acid. Data were analyzed statistically by ANOVA and Tukey's test at $5 \%$ significance level. There was no significant differences $(\mathrm{p}<0.05)$ among the groups in any of the conditions for hydraulic conductance reduction, except for smear layer presence. The active agents reduced dentin permeability, but they produced significantly lower $(p<0.05)$ reduction in hydraulic conductance when compared to presence of smear layer. The effectiveness in reducing dentin permeability was not significantly different ( $\mathrm{p}>0.05)$ among the gels. This study suggests that the iron gel promoted reduction in dentin permeability comparable to that of the other agents and thus may be considered a good clinical alternative for the treatment of dentin hypersensitivity.
\end{abstract}

Key Words: dentin, dentin permeability, dentin sensitivity.

\section{INTRODUCTION}

Patients have retained their natural teeth for a longer time due to effective preventive and treatment strategies for caries and periodontal disease (1). The increased longevity of dentition may increase the incidence of dentin hypersensitivity (2). Several agents and therapies have been proposed for the treatment of dentin hypersensitivity, however none of them have been shown to be completely efficient $(2,3)$.

The effect of iron on reducing enamel and dentin demineralization by acids has been suggested $(4,5)$. However, the mechanism involved in the protective action of iron against mineral dissolution is not completely understood. It is possible that the formation of a thin acid-resistant coating of hydrous iron oxide on the enamel mineral surface could be a factor (5). Other hypotheses have been suggested, such as participation in human enamel remineralization and apatite nucleation (6), substitution of calcium in apatite, increased concentration in remineralized caries lesions in enamel and dentin (7) and inhibition of demineralization (6). In contrast to enamel, erosion in dentin seems to be more than a surface phenomenon. The eroded dentin has a complex histological structure, and its organic fraction becomes increasingly exposed as a result of the continual action of acids (8).

Erosion in dentin, differently from that in enamel, seems to be more than a surface phenomenon (9). Scanning electron and tomographic microscopy studies have shown that demineralization of dentin first becomes apparent at the interface between inter- and peritubular dentin and, with the increase of the exposure time, results in a hollowing and funneling of the tubules. Finally, the peritubular dentin is completely dissolved. The innermost sound dentin is then followed by a zone of partly demineralized dentin until a layer of completely demineralized collagen amounting up to one third of the total etching depth is reached $(10,11)$. The presence of this demineralized organic layer may hamper ionic diffusion influencing demineralization(9). A previous in

Correspondence: Profa. Dra. Sílvia Helena de Carvalho Sales-Peres, Departamento de Odontopediatria Ortodontia e Saúde Coletiva, Faculdade de Odontologia de Bauru, USP, Alameda Octávio Pinheiro Brisolla, 9-75, 17012-901 Bauru, SP, Brasil. Tel: +55-14-3235-8260. Fax: +55-14-32358260. e-mail: shcperes@usp.br 
situ/ex vivo study showed that dentin demineralization was significantly reduced in the presence of iron (4). Thus, it seems likely that the ferric phosphate layer described above for enamel may have been deposited onto the collagen layer, rendering it more resistant to abrasive forces. Those authors (4) suggested that an iron rinse after an erosive attack, followed or not by an abrasive challenge, may be a feasible alternative to reduce the loss of dental structure.

Considering that no studies have been reported on the in vitro effect of iron sulfate gel on dentin permeability, the aim of this study was to evaluate in vitro the variations in the hydraulic conductance of dentin after treatment with $1.23 \%$ acidulated phosphate fluoride gel, a commercial potassium oxalate gel and an experimental iron sulfate gel. The null hypothesis tested was that the iron gel does not reduce the hydraulic conductance of dentin, in vitro.

\section{MATERIAL AND METHODS}

This research was approved by the Research Ethics Committee of the Bauru Dental School, University of São Paulo (Protocol\#10/2007). The teeth were obtained from the Human Tooth Bank of the same institution.

Forty sound human third molars extracted for surgical reasons from young patients (mean age $=22$ years) were stored in $0.1 \%$ thymol (Merck, Darmstadt, Germany) at $4{ }^{\circ} \mathrm{C}$ to inhibit microbial growth, being used within 1 month of recorded extraction. The crowns were sectioned with a diamond saw in a precision cutting machine (Isomet 1000; Buehler, Lake Bluff, IL, USA) perpendicular to the long axis of the roots to create dentin discs from mid-coronal dentin. Thirty-six dentin discs were obtained from the extracted teeth and 30 were used. The smear layer created by the diamond saw was removed with 400-600 grit $\mathrm{SiC}$ abrasive paper (Buehler), resulting in dentin discs approximately $0.98 \pm$ $0.08 \mathrm{~mm}$ thick, as measured with a micrometer accurate to $0.01 \mathrm{~mm}$. Disc surface was free of coronal enamel and with no evidence of pulp horns (2). The specimens were immersed in 37\% phosphoric acid solution for 15 $\mathrm{s}$ to remove the 600-grit $\mathrm{SiC}$ smear layer on both sides of the discs. Using 320-grit $\mathrm{SiC}$ abrasive paper in a rotary polisher (125 rpm) for $5 \mathrm{~s}$, a standard smear layer was then produced on the occlusal surface of the discs. Each dentin disc was placed in a split-chamber device that allowed the standardization of exposed dentin area by using pairs of rubber "O" rings that provided 0.178 or $0.282 \mathrm{~cm}^{2}$ of available surface area for filtration of deionized water. These areas depended on the size of dentin discs. Hydrostatic pressure of $703.1 \mathrm{cmH}_{2} \mathrm{O}$ was applied and the rate of fluid movement across dentin (filtration) was measured by following the progress of a small air bubble in a micropipette lying on top of a millimeter scale $(2,10)$.

Dentin permeability was measured by water filtration and expressed in terms of hydraulic conductance using the method suggested by Pashley and Galloway (10). Deionized water filtration across the dentin was measured after each of the following situations: in the presence of smear layer, representing the minimum permeability; after smear layer removal with $37 \%$ phosphoric acid for $1 \mathrm{~min}$ to obtain the maximum permeability; after 4 min of passive application of the desensitizing agents; after application of $6 \%$ citric acid (Merck) for $1 \mathrm{~min}$, to determine how susceptible the treatment with the agents was to acid challenge.

Two basic conditions were taken into account before testing the effect of the agents on dentin hydraulic conductance. First, it is known that the presence of smear layer is the most effective condition to occlude the dentin tubules and reduce liquid flow through dentin. The second condition, demineralization allows greater dentin permeability. The hydraulic conductance was initially measured in the presence of a smear layer to assess minimum permeability, and subsequently the dentin discs were etched in order to establish the maximum permeability values of each specimen individually. Maximum permeability values were considered $100 \%$ filtration of each specimen. The other values, including the effects of gel and smear layer were calculated as a proportion of $100 \%$ permeability. After maximum permeability was determined, the desensitizing agents were applied to dentin disc surface for $4 \mathrm{~min}$, and thoroughly rinsed with deionized water. The filtration was measurement made for each condition and the percentage relative to maximum permeability was calculated using the following equation:

$\mathrm{LP}=\mathrm{Q} / \mathrm{P}(\mathrm{SA})$, where $\mathrm{Lp}=$ hydraulic conductance of dentin in $\mu \mathrm{L} \mathrm{cm}{ }^{-2} \min -1 . \mathrm{cmH}_{2} \mathrm{O}$; $\mathrm{Q}=$ filtration rate in $\mu \mathrm{L} \mathrm{min}{ }^{-1} ; \mathrm{SA}=$ surface area in $\mathrm{cm}^{2} ; \mathrm{P}=$ hydrostatic pressure across dentin in $\mathrm{cmH}_{2} \mathrm{O}$ The velocity and time of bubble movement are variables and the capillary volume and internal diameter, hydrostatic pressure and surface area are constants.

The 30 dentin discs were randomly assigned to 3 groups of 10 specimens each, according to the 
desensitizing agent: $1.23 \%$ acidulated phosphate fluoride gel, $\mathrm{pH} 4.1$ (prepared at a prescription pharmacy); $3 \%$ potassium oxalate monohydrate plus carboxymethylcellulose, pH 4.1 (Oxa-Gel ${ }^{\circledR}$; Art D Ind. Com. Produtos Odontológicos, Araraquara, SP, Brazil); and an experimental iron sulfate gel $\left(10 \mathrm{mmol} / \mathrm{LFeSO}_{4}\right)$, pH 4.1 (prepared at a prescription pharmacy).

All desensitizing agents were applied for $4 \mathrm{~min}$, to follow the manufacturer's instructions for Oxa-Gel and then rinsed with deionized water. After the hydraulic conductance was measured under the above conditions, the specimens were exposed to $6 \%$ citric acid $\mathrm{pH} 2.1$ for $1 \mathrm{~min}$ and the filtration was measured again. The aim of this treatment was to evaluate the resistance of the possible occlusive effect of the studied materials to an acidic environment, similar to that found in the mouth. The hydraulic conductance of each condition was determined four times in succession and the mean value determined and expressed as percent of the maximum Lp.

\section{Statistical Analysis}

Statistica 7.0 software (StatSoft, Tulsa, OK, USA) was used. Data were tested by two-way ANOVA at 5\% significance level, applied to the reductions in hydraulic conductance to detect differences between the conditions studied. Significant differences were found between materials, conditions and interaction materials $\mathrm{X}$ conditions. Individual comparisons by Tukey's test at $5 \%$ significance level identified the differences.

\section{RESULTS}

The effectiveness of the desensitizing gels on dentin permeability reduction was analyzed by two-way ANOVA, but no significant differences $(\mathrm{p}>0.05)$ were found among the gels.

Although the gels caused some reduction in the hydraulic conductance of phosphoric acid-etched dentin they did not differ significantly ( $p>0.05$ ) from each other.

Table 1 shows the mean hydraulic conductance values $( \pm \mathrm{SD})$ of the groups. Desensitizing effect was observed for all the groups (Fluoride gel $=0.21 \pm 0.11$; Oxa-Gel $=0.17 \pm 0.06$; Iron gel $=0.29 \pm 0.17$, which had very similar behavior and did not differ significantly $(p>0.05)$ from each other.

There was significant difference $(p<0.05)$ in dentin permeability between smear layer and the gels. Table 1 shows that the effect of gels after acid challenge revealed no differences among the groups ( $p>0.05$ ).

\section{DISCUSSION}

Dentin hypersensitivity is a frequent problem in the dental clinic (12). This condition may disturb the patient during eating, drinking, tooth brushing and sometimes even when breathing. Therapeutic intervention with desensitizing agents may provide only partial pain relief and recurrence is common $(12,13)$.

Due to the protective effect of iron on dental surface dissolution $(4,14,15)$, the present study used gel as a vehicle to deliver iron to the dental structure, in order to prevent further dentin sensitivity. Thus the null hypothesis was rejected.

The significant influence of the collagen layer on dentin wear may be associated with the effect of dentin matrix metalloproteinases (MMP) (16). A recent study showed that iron sulfate was able to inhibit MMP in vitro (17). The mechanism of action of the iron sulfate gel for reducing dentin permeability was not directly evaluated in this study. However, it is possible that iron sulfate had some action on the inhibition of dentin MMP.

Table 1. Means $(\%)$ of hydraulic conductance $( \pm \mathrm{SD})$ for each gel type as an after acid challenge as well as minimum and maximum (100\%) hydraulic conductance, and Tukey's test comparison.

\begin{tabular}{|c|c|c|c|c|c|c|c|c|}
\hline & \multicolumn{2}{|c|}{ Fluoride gel (F) } & \multicolumn{2}{|c|}{ Oxa-gel (O) } & \multicolumn{2}{|c|}{ Iron gel (I) } & \multicolumn{2}{|c|}{ All gels } \\
\hline & mean $\pm \mathrm{SD}$ & $\%$ & mean $\pm \mathrm{SD}$ & $\%$ & mean $\pm \mathrm{SD}$ & $\%$ & mean \pm SD & $\%$ \\
\hline Minimum & $0.01 \pm 0.00$ & 9.05 & $0.03 \pm 0.04$ & 11.61 & $0.06 \pm 0.15$ & 16.94 & $0.25 \pm 0.13$ & $14.16^{\mathrm{a}}$ \\
\hline Maximum & $0.24 \pm 0.12$ & 100.00 & $0.21 \pm 0.09$ & 100.00 & $0.34 \pm 0.19$ & 100.00 & $0.36 \pm 0.09$ & $100.00^{b}$ \\
\hline Gel & $0.21 \pm 0.11$ & 86.10 & $0.17 \pm 0.06$ & 82.61 & $0.29 \pm 0.17$ & 84.01 & $0.21 \pm 0.11$ & $84.65^{b}$ \\
\hline Acid challenge & $0.20 \pm 0.11$ & 78.70 & $0.16 \pm 0.06$ & 80.89 & $0.32 \pm 0.19$ & 93.68 & $0.22 \pm 0.13$ & $86.19^{b}$ \\
\hline
\end{tabular}

Different letters in the same column indicate statistically significant difference among the experimental conditions ( $\mathrm{p}<0.05$ ). 
In present study, there was some effect of iron gel on reducing or minimizing dentin permeability, but no significance difference among all active materials. Thus, it is possible that effect of iron gel on dentin permeability decrease in our experiment might be partially attributed to its effect on dentin MMP inhibition, as demonstrated elsewhere (17). This should be further investigated.

Fluoride was included in the present study due to its capacity of reactivity to dentin. In addition, Oxagel, which is considered in the literature to be efficient in reducing dentin permeability, was used as positive control $(2,12,13)$. In this in vitro study, the device used to assess dentin hydraulic conductance was proposed by Pashley and Galloway (10). The limitations imposed by the method should be considered, thus it depended on an initial clustering of the specimens, which were standardized for all other comparisons, starting with the smear layer, followed by phosphoric acid gel application, application of the agents and finally application of citric acid.

According to Pashley et al. (18), the minimum permeability of the specimens is determined by the presence of smear layer occluding the dentin tubules, allowing minimal transdentinal movement of fluids. The authors reported that the presence of smear layer on dentin surface is responsible for $86 \%$ of the total resistance to fluid movement across dentin. The maximum permeability is determined by the removal of smear layer by demineralization, which causes a significant increase in fluid filtration through the dentin.

Increased intratubular resistance may occur under high pressures due to compression of internal contents of tubules against tubule walls, reducing the hydraulic conductance values (2). The analyses showed that there was statistical significance between the tested gels and smear layer (Table 1), however the products tested seemed to have little effect on the reduction of dentin hydraulic conductance. The fluoride gel reduced dentin permeability by $86.11 \%$, Oxa-gel by $82.61 \%$ and the iron gel by $84.01 \%$. These results indicate that they had a similar action on dentin hydraulic conductance.

This fact revealed that the products tested had low action in reducing dentin permeability. However, they underwent the same protocol in vitro, showing similarity in action. Further studies should be conducted so that the scientific evidence is conclusive.

Citric acid application after gel was made with aim of simulating the resistance of gels to acid attack caused by acid foods and drinks. Table 1 shows no significant difference among the 3 gels after citric acid application. These findings reinforces the hypothesis that all the tested gels offered some resistance to the acid challenge. The protection offered by the tested gels remained the same under acidic conditions, allowing the use of these products on exposed dentin. Further studies will be conducted to reach conclusive scientific evidence.

The iron gel was proposed as an agent for reducing dentin permeability, considering that some studies have shown that this concentration of iron can reduce the demineralization of tooth enamel in an acid $\mathrm{pH}(4,14,15)$. Several in vitro and in situ studies have used the iron in an attempt to reduce tooth wear $(4,5,14)$. The iron gel caused a significant reduction in enamel microhardness, and a significant reduction in wear in dentin. Thus, the iron seems to promote ion exchange and deposit on the exposed dentin, thereby reducing dentin sensitivity (4).

This aspect is relevant, not only in erosion experiments, but also in dentin permeability studies. The present study was the first to evaluate the incorporation of iron into dental gels for decreasing dentin permeability.

Acidulated phosphate fluoride gel and potassium oxalate are products with an obstructive effect, and the gel most used in the treatment of dentin hypersensitivity is potassium oxalate. It should be noted that ferrous sulfate showed similar protection to that of other gels.

Application of an acidic solution of oxalate to form small insoluble crystals of calcium oxalate within dentin tubules restricts fluid movement across dentin and has been used to desensitize dentin (19).

Several in vitro $(2,10)$ and in vivo (20) studies have shown that potassium oxalate is an effective dentin occluding agent and thus reduces dentin sensitivity. This product has two mechanisms for desensitizing dentin: it has the effect of occluding dentin, as a result of the potassium oxalate crystals creating plugs at the tubule entrances, and it reduces the neural action (21).

Indeed, previous studies have reported the incapacity of dental products avoiding loss of dentin structure $(20,21)$. In the present study, the experimental iron gel showed similar action in reducing dentin permeability than that of fluoride gel and Oxa-gel. Thus, it can be recommended as another alternative agent to treat dentin sensitivity. In addition, the iron gel presents desirable characteristics such as being easy to apply, having low cost and having prolonged action, as it maintains the same effect on dentin permeability after acid challenge.

The results of the present study showed no 
significant difference in hydraulic conductance (obliteration of dentin tubules) among the 3 gels tested. However, this was the first study to use iron gel as a treatment for dentin hypersensitivity.

Previous studies $(4,14,15)$ have shown that iron was able to increase enamel and dentin resistance to acidic drinks. Thus, the iron gel formulation could be used with success for treating dentin sensitivity. This study opens a perspective for the desensitizing action of iron to reduce the dentin hydraulic conductance rate.

The null hypothesis tested was rejected because the iron gel reduced the hydraulic conductance of dentin, in vitro. Thus, iron sulfate gel may be considered a good clinical alternative for the treatment of dentin hypersensitivity. Further studies are required to substantiate the effects of iron under clinical conditions.

\section{RESUMO}

Este estudo objetivou avaliar in vitro o efeito do gel experimental contendo ferro na redução da condutividade hidráulica na dentina. Trinta e seis discos de dentina humana de $1 \mathrm{~mm}$ de espessura, foram obtidos de terceiros molares extraídos divididos em 3 grupos de 10 espécimes cada. Os grupos foram divididos nos seguintes grupos experimentais: F- flúor gel a 1,23\%, pH 4,1; O- gel de oxalato de potássio a $3 \%$, $\mathrm{pH} 4,1$; I- gel de sulfato ferroso $\mathrm{FeSO}_{4}$ a $10 \mathrm{mmol} / \mathrm{L}, \mathrm{pH} 4,1$. Os géis foram aplicados na dentina sob as diferentes condições: após o ácido fosfórico a 37\% a antes do ácido cítrico a $6 \%$. Os resultados foram analisados por ANOVAe teste de Tukey, com nível de significância de $5 \%$. Todos os grupos (gel de flúor, oxalato de potássio e gel de ferro) não apresentaram diferenças significativas entre si para todas as condições testadas, exceto na presença da smear layer $(\mathrm{p}<0,05)$. Os produtos utilizados reduziram a permeabilidade dentinária, entretanto apresentaram baixa redução quando comparados à smear layer $(\mathrm{p}<0,05)$. Não houve diferença significativa na efetividade dos géis testados para reduzir a permeabilidade dentinária $(p<0,05)$. Este estudo sugere que o gel de ferro promoveu redução na permeabilidade dentinária comparável à dos outros agentes e, portanto, pode ser considerada uma boa alternativa clínica para o tratamento da hipersensibilidade dentinária.

\section{ACKNOWLEDGEMENTS}

This work was supported by a grant from CNPq (Brazilian National Research Council) and FAPESP (The São Paulo State Research Foundation). The authors are grateful to Prof. Dr. José Carlos Pereira for his assistance in hydraulic conductance analysis.

\section{REFERENCES}

1. Pinto SC, Batitucci RG, Pinheiro MC, Zandim DL, Spin-Neto R, Sampaio JE. Effect of an acid diet allied to sonic toothbrushing on root dentin permeability: an in vitro study. Braz Dent J 2010;21:390-395.
2. Santiago SL, Pereira JC, Martineli AC. Effect of commercially available and experimental potassium oxalate-based dentin desensitizing agents in dentin permeability: influence of time and filtration system. Braz Dent J 2006;17:300-305.

3. Gillam DG, Newman HN, Davies EH, Bulman JS, Troullos ES, Curro FA. Clinical evaluation of ferric oxalate in relieving dentine hypersensitivity. J Oral Rehabil 2004;31:245-250.

4. Sales-Peres SH, Pessan JP, Buzalaf MA. Effect of an iron mouthrinse on enamel and dentine erosion subjected or not to abrasion: an in situ/ex vivo study. Arch Oral Biol 2007;52:128-132.

5. Torell P. Iron and dental caries. Swed Dent J 1988;12:113-124.

6. Bachra BN, van Harskamp GA. The effect of polyvalent metal ions on the stability of a buffer system for calcification in vitro. Calcif Tissue Res 1970;4:359-365.

7. Driessens FC, Theuns HM, Heijligers HJ, Borggreven JM. Microradiography and electron microprobe analysis of some natural white and brown spot enamel lesions with and without laminations. Caries Res 1986;20:398-405.

8. Ganss C, Hardt M, Blazek D, Klimek J, Schlueter N. Effects of toothbrushing force on the mineral content and demineralized organic matrix of eroded dentine. Eur J Oral Sci 2009;117:255260.

9. Meurman JH, Drysdale T, Frank RM. Experimental erosion of dentin. Scand J Dent Res 1991;99:457-462.

10. Pashley DH, Galloway SE. The effects of oxalate treatment on the smear layer of ground surfaces of human dentine. Arch Oral Biol 1985;30:731-737.

11. Kinney JH, Balooch M, Haupt DL Jr., Marshall SJ, Marshall GW Jr.. Mineral distribution and dimensional changes in human dentin during demineralization. J Dent Res 1995;74:1179-1184.

12. Dababneh RH, Khouri AT, Addy M. Dentine hypersensitivity - an enigma? A review of terminology, mechanisms, aetiology and management. Br Dent J 1999;187:606-611.

13. Walters PA. Dentinal hypersensitivity: a review. J Contemp Dent Pract 2005;6:107-117.

14. Bueno MG, Marsicano JA, Sales-Peres SH. Preventive effect of iron gel with or without fluoride on bovine enamel erosion in vitro. Aust Dent J. 2010;55:177-180.

15. Kato MT, de Moraes Italiani F, de Araujo JJ, Garcia MD, de Carvalho Sales-Peres SH, Buzalaf MA. Preventive effect of an iron varnish on bovine enamel erosion in vitro. J Dent 2009;37:233236.

16. Sulkala M, Tervahartiala T, Sorsa T, Larmas M, Salo T, Tjaderhane L. Matrix metalloproteinase-8 (MMP-8) is the major collagenase in human dentin. Arch Oral Biol 2007;52:121-127.

17. Kato MT, Leite AL, Hannas AR, Oliveira RC, Pereira JC, Tjaderhane L, et al.. Effect of iron on matrix metalloproteinase inhibition and on the prevention of dentine erosion. Caries Res 2010;44:309-316.

18. Pashley DH, Livingston MJ, Greenhill JD. Regional resistances to fluid flow in human dentine in vitro. Arch Oral Biol 1978;23:807810.

19. Orchardson R, Gillam DG. Managing dentin hypersensitivity. J Am Dent Assoc 2006;137:990-998.

20. Muzzin KB, Johnson R. Effects of potassium oxalate on dentin hypersensitivity in vivo. J Periodontol 1989;60:151-158.

21. Pashley DH. Dentin permeability, dentin sensitivity, and treatment through tubule occlusion. J Endod 1986;12:465-474.

Accepted April 4, 2011 